\title{
FORMULATION AND CHARACTERIZATION OF SUSTAINED RELEASE TABLET USING MARDI GUM
}

\author{
MANGESH M KUMARE ${ }^{1 *}$, GIRIDHAR R SHENDARKAR ${ }^{2}$ \\ ${ }^{1}$ Department of Pharmacy, Smt. Kusumtai Wankhede Institute of Pharmacy, Katol, Maharashtra, India. ${ }^{2}$ Department of Pharmacy, Nanded \\ Pharmacy College, Nanded, Maharashtra, India. Email: kmangesh008@gmail.com
}

Received: 17 February 2021, Revised and Accepted: 25 March 2021

\section{ABSTRACT}

Objective: The present research work was to develop and evaluate alprazolam sustained release tablet using Mardi gum, a comparative study on binding properties of gum and hydroxypropyl methylcellulose (HPMC) was performed.

Methods: Formulation of alprazolam tablets (f1-f6) was done by direct compression method using 15\%, 30\%, and 45\% concentration of gum as a natural binder, and HPMC was used as synthetic matrix forming agent. Microcrystalline cellulose was used as diluents, talc, and magnesium stearate as a lubricant and PVP K30 as the binder. The formulated batches were evaluated for parameters such as tablet thickness, \% friability, hardness, weight variation, and in vitro drug release characteristics. The release information was fitted into different dynamics models to decide the release mechanism of the drug.

Results: The results showed that all the parameters of the developed tablets (f1-f6) were in fulfillment with pharmacopeia limits. In vitro, drug release studies showed that formulation $\mathrm{f} 1$ had most controlled and sustained manner releaser with maximum drug release of $97.89 \pm 0.52 \%$ in 18 $\mathrm{h}$ with comparison to f2-f4 and f6 drug release is $98.12 \pm 0.55 \%, 97.24 \pm 0.57 \%, 98.16 \pm 0.74 \%$, and $97.26 \pm 0.35 \%$, respectively, in $16 \mathrm{~h}$ and f5 giving $97.89 \pm 0.85 \%$ release in $14 \mathrm{~h}$.

Conclusion: On the basis of obtained result, it can be concluded that Mardi gum can be used to sustain the drug release as a natural polymer in tablet dosage form.

Keywords: Alprazolam, Mardi gum, Matrix tablets, Natural polymer, Sustain.

(C) 2021 The Authors. Published by Innovare Academic Sciences Pvt Ltd. This is an open access article under the CC BY license (http://creativecommons.org/ licenses/by/4.0/) DOI: http://dx.doi.org/10.22159/ajpcr.2021v14i5.41138. Journal homepage: https://innovareacademics.in/journals/index.php/ajpcr

\section{INTRODUCTION}

Sustained release delivery system is increasingly being used in the treatment of acute and chronic diseases as they maintain the concentration of drug in plasma above the minimum effective concentration to and below the minimum toxic level for an extended period of time [1,2]. The development of sustained release drug delivery systems has broad been a major area of research in the pharmaceutical industry. Sustained release drug delivery design involves the exploitation of physical and polymer chemistry to dosage form design to formulate well-characterized and reproducible units that control drug delivery into the body within the specification of the required drug delivery profile [3]. Nature provides a noteworthy collection of polymeric materials that have been finding very attractive applications in the biomedical field, as they are well known to perform a varied set of functions in their inhabitant environment [4]. Gadchiroli of Vidarbha region in Maharashtra state is one of the nature surrounding areas, which is well-known forest area having tree with gummy exudates. In the present study, sustained release tablets of alprazolam using exudates from the tree of Terminalia tomentosa were prepared to see its application as a release retardant. Sustained release tablets were prepared using natural gum Mardi and synthetic polymer hydroxypropyl methylcellulose (HPMC) by employing a direct compression method. The objective of the work was to explore a novel natural binding agent and to formulate sustained released tablets of alprazolam so as to reduce its frequent administration and to improve patient compliance. Hence, the novelty of the proposed work is the use of Mardi gum as the matrix forming agent to delay the release of the drug.

\section{METHODS}

Material alprazolam obtained as a gift sample from Lake Chemicals Pvt. Ltd., Bengaluru, and microcrystalline cellulose $\mathrm{pH}$ 102, talc, magnesium stearate, and PVP K30 were obtained as a gift sample from Relief Lab Pvt. Ltd., Kalmeshwar, and HPMC from Loba Chemie Pvt. Ltd., Mumbai, India. All other chemicals used were of analytical grade.

\section{Collection and purification of gum exudates}

As the authors described elsewhere, gums were collected from the plants of T. tomentosa (Mardi), Mardi was subjected to the stress by making incisions on the trunk in the $1^{\text {st }}$ week of January, and gum was collected in the month of February and March. Collected gum exudates were treated with petroleum ether and chloroform (to remove pigments and chlorophyll) and then carefully washed with distilled water, dried under shade for $24 \mathrm{~h}$, further dried at $30-40^{\circ} \mathrm{C}$ until a constant weight was obtained. The size was reduced through the grinder. Powdered gum passed through sieve no. \#22 and stored in an airtight container for further use. The gums were then precipitated from the solution using acetone. The precipitate was separated, dried in the oven at $50^{\circ} \mathrm{C}$, and stored in a tightly closed container for future use as a binder in formulating matrix tablets [5].

\section{Characterization of drug and excipients}

An infrared spectrum was taken by scanning the samples of pure drug and the polymers individually over a wavenumber range of 4000$400 \mathrm{~cm}^{-1}$ using Fourier transform infrared spectrophotometer (FT-IR, Shimadzu 8400S, Shimadzu, Japan). The change in spectra of the drug in the presence of polymer was investigated which indicates the physical interaction of the drug molecule with the polymer [6].

\section{Preparation of alprazolam tablet}

The sustained release matrix tablet of alprazolam was prepared using the direct compression method. A variety of concentrations $15 \%, 30 \%$, and $45 \%$ of natural and synthetic polymers was used. Total seven 
formulations were developed using constant $200 \mathrm{mg}$ of alprazolam with amounts of excipients. The polymers being used in the formulation are HPMC and Mardi gum from T. tomentosa which is given in Table 1.

\section{Pre-compression parameters}

The prepared powder blend was evaluated for various parameters such as angle of repose, loose bulk density, tapped bulk density, and compressibility index [7-9].

\section{Post-compression parameters}

All prepared matrix tablets were evaluated for their uniformity of hardness, weight, friability, and thickness according to official methods. Tablet hardness was determined for 10 tablets using a Monsanto tablet

Table 1: Composition of tablet

\begin{tabular}{lllllll}
\hline Ingredients & \multicolumn{7}{l}{ Batch } & & & & \\
\cline { 2 - 7 } & F1 & F2 & F3 & F4 & F5 & F6 \\
\hline Alprazolam (mg) & 3 & 3 & 3 & 3 & 3 & 3 \\
Gum (mg) & 30 & 60 & 90 & - & - & - \\
Hydroxypropyl methylcellulose & - & - & - & 30 & 60 & 90 \\
(mg) & & & & & & \\
Microcrystalline cellulose (mg) & 153 & 123 & 93 & 153 & 123 & 93 \\
PVP K30 (mg) & 10 & 10 & 10 & 10 & 10 & 10 \\
Talc (mg) & 2 & 2 & 2 & 2 & 2 & 2 \\
Mg stearate (mg) & 2 & 2 & 2 & 2 & 2 & 2 \\
\hline
\end{tabular}

hardness tester; thickness was measured by Vernier caliper. Friability was determined by Roche friabilator. The weight variation was determined by taking 20 tablets using an electronic balance all ridings noted in triplicate [10].

Drug content was determined by taking $50 \mathrm{mg}$ equivalent weighed of alprazolam in tablet powder which was accurately weighted and transferred into a $100 \mathrm{ml}$ volumetric flask. At first, $10 \mathrm{ml}$ of phosphate buffer (pH 6.8) was added and shaken for $10 \mathrm{~min}$. After that, the volume was made up to $100 \mathrm{ml}$ with buffer. Subsequently, the solution in the volumetric flask was filtered, and $1 \mathrm{ml}$ of the filtrate was diluted and analyzed at $255 \mathrm{~nm}$ using a UV-visible spectrophotometer (Shimadzu, Japan). The drug content of each sample was estimated from their standard curve.

\section{In vitro dissolution studies}

In vitro dissolution studies of tablets were studied in USP XXIII tablet dissolution test apparatus-I (Electrolab) employing a basket stirrer, $500 \mathrm{ml}$ of $0.1 \mathrm{pH}$ buffer was used as a dissolution medium for the first $1 \mathrm{~h}$ and replaced with 6.8 phosphate buffer for a specified time which is stirred at $50 \mathrm{rpm}$. The temperature of the dissolution medium was previously warmed to $37 \pm 0.5^{\circ} \mathrm{C}$ and was maintained throughout the experiment. One tablet was used in each test. Five milliliters sample of dissolution medium was withdrawn by means of a syringe fitted with a pre-filter at known intervals of time $(1 \mathrm{~h})$. The sample was analyzed for drug release by measuring the absorbance at $255 \mathrm{~nm}$ using UV-visible spectrophotometer Shimadzu-1700 after suitable dilutions.

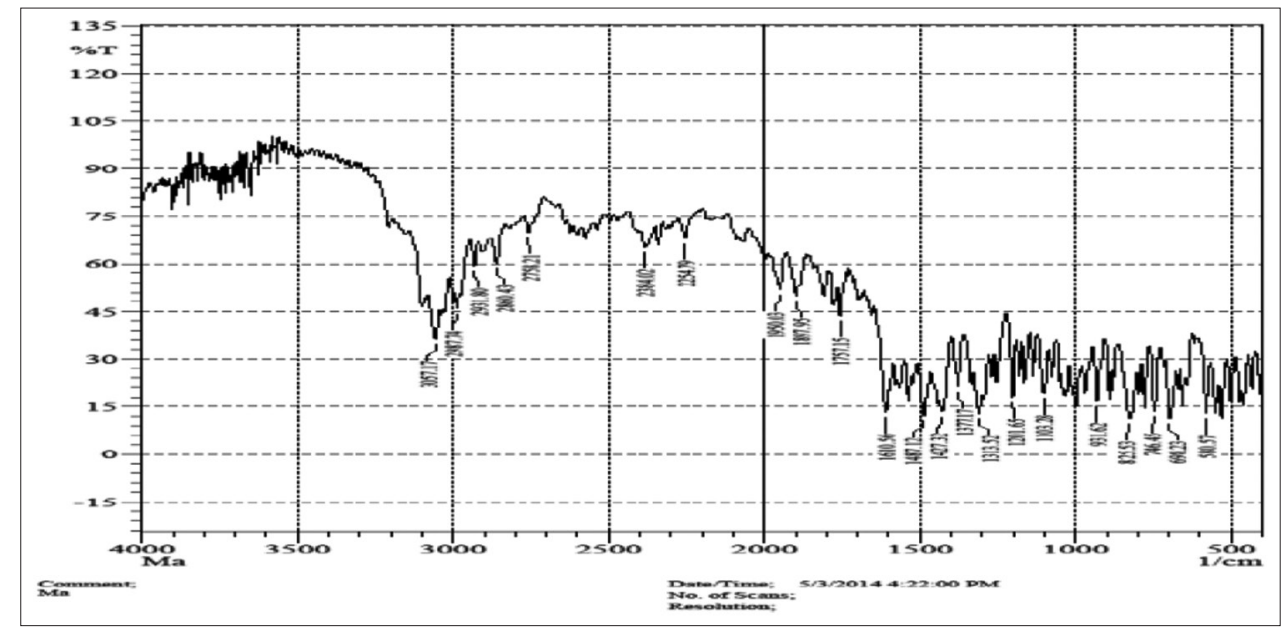

Fig. 1: FTIR spectrum of alprazolam

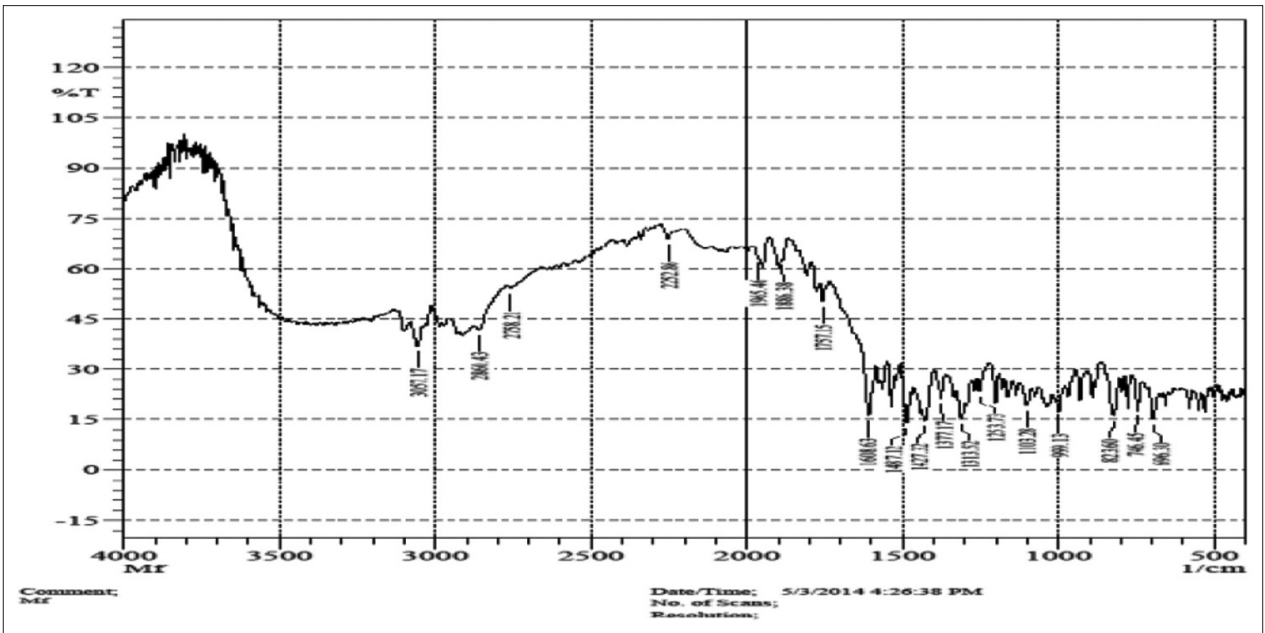

Fig. 2: FTIR spectrum of alprazolam with polymers blends 
The volume withdrawn at each interval was replaced with the same quantity of dissolution medium [11].

\section{Drug release kinetics}

To study the release kinetics, data obtained from in vitro drug release studies were plotted in various kinetic models: Zero order as the cumulative amount of drug release versus time, first-order as log cumulative percentage of drug remaining versus time, and Higuchi's model as cumulative percentage of drug released versus square root of time and Korsmeyer-Peppas model, etc.

\section{Uniformity of drug content}

The test is mandatory for tablets with $10 \mathrm{mg}$ or less weight of the active ingredient. From each batch, 10 tablets were randomly selected and

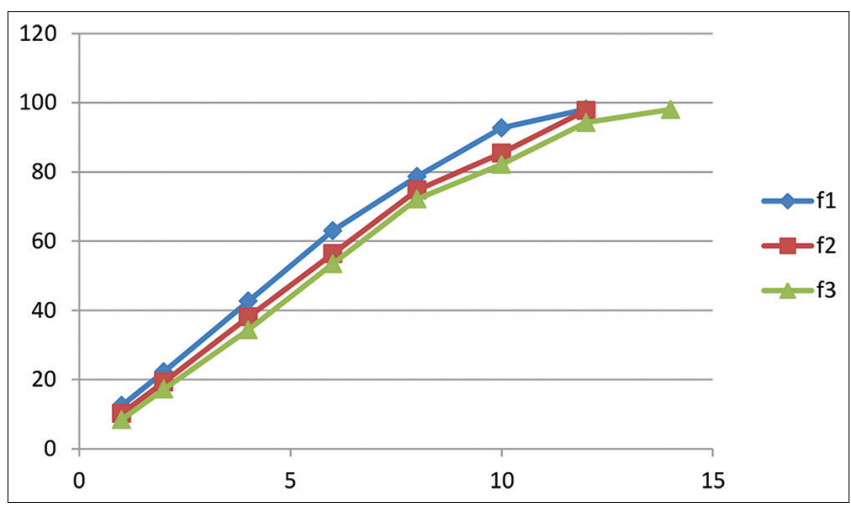

Fig. 3: In vitro release with Mardi gum

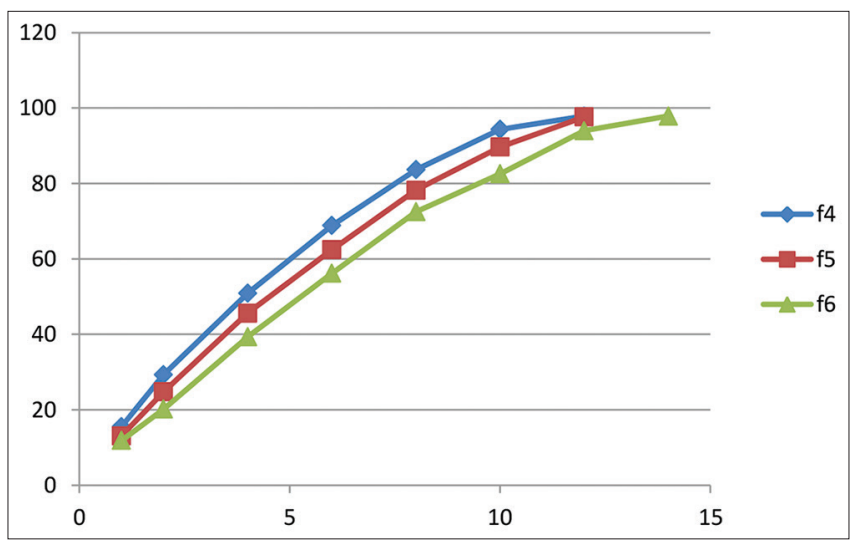

Fig. 4: In vitro release with hydroxypropyl methylcellulose finely powdered, and dissolved in $10 \mathrm{ml}$ of 6.8 phosphate buffer. Sonicate it for $20 \mathrm{~min}$, till the entire drug leached out from the complex, and then the solution was filtered through Whatman filter paper No. 41. From this solution, take $1 \mathrm{ml}$ and diluted up to $100 \mathrm{ml}$ with 6.8 phosphate buffer and the drug content was determined spectrophotometrically at $255 \mathrm{~nm}$ for alprazolam.

\section{Stability studies of optimize formulation}

The prepared tablets were packed and subjected to stability studies at $40 \pm 2{ }^{\circ} \mathrm{C} / 75 \pm 5 \% \mathrm{RH}$ and $30 \pm 2^{\circ} \mathrm{C} / 60 \pm 5 \% \mathrm{RH}$ as per ICH guidelines for a period of 6 months. Samples were withdrawn at 1 month time intervals and evaluated for physical appearance, drug content, and in vitro drug release.

\section{RESULTS AND DISCUSSION}

\section{Characterization of drug and excipients}

To determine possible interaction between the alprazolam drug, Mardi gum, and other excipients used in the formulation, compatibility studies were conducted using FTIR spectroscopy. There was no significant shift in the positions of the wave numbers when compared to that of the pure drug values. Thus, there was no interaction between the drug and other excipients of the formulation. FTIR spectra are shown in Figs. 1 and 2.

\section{Pre-compression parameters}

Powder blend prepared for compression of sustained release tablets of alprazolam was evaluated for their flow properties such as the angle of repose, loose bulk density, tapped bulk density, and compressibility index. The results were shown, Table 2 . The angle of repose was in the range of $28-30^{\circ}$. The loose bulk densities of the granules were in the range of $0.369-0.398 \mathrm{~g} / \mathrm{ml}$. The bulk density was in the range of $0.455-0.472 \mathrm{~g} / \mathrm{ml}$, which indicates that the powder was not bulky. The compressibility index was found to be in the range of $15.38462-$ 21.82203 .

\section{Post-compression parameters}

The results of the physical properties of alprazolam sustained release matrix tablets are presented Table 3. The thickness was measured by Vernier caliper and was ranged between $4.02 \pm 0.2 \mathrm{~mm}$ and $4.25 \pm 0.2 \mathrm{~mm}$. The diameter of tablets was measured by Vernier caliper and was ranged between $8.02 \pm 0.02 \mathrm{~mm}$ and $8.22 \pm 0.05 \mathrm{~mm}$. The hardness of the tablets was measured by Monsanto tester and was controlled between $4.6 \mathrm{~kg} / \mathrm{cm}^{2}$ and $5.8 \mathrm{~kg} / \mathrm{cm}^{2}$. The friability was below $1 \%$ for all the formulations. The percentage of drug content for $\mathrm{f} 1-\mathrm{f} 6$ was found to be between $98.33 \pm 0.51 \%$ and $99.83 \pm 0.21 \%$ of alprazolam, it complies with the official specification. Thus, all the physical attributes of the prepared tablets of alprazolam were found be practically within control. Weight variations for different

Table 2: Results of the evaluation of powder blends

\begin{tabular}{|c|c|c|c|c|c|}
\hline Formulations & Angle of repose $\left(^{\circ}\right)$ & Bulk density $(\mathrm{g} / \mathrm{ml})$ & Tapped density $(\mathrm{g} / \mathrm{ml})$ & Carr's index (\%) & Hausner ratio \\
\hline F1 & 29 & 0.399 & 0.469 & 14.9253 & 1.1754 \\
\hline $\mathrm{F} 2$ & 30 & 0.365 & 0.442 & 17.4208 & 1.2109 \\
\hline F3 & 30 & 0.389 & 0.463 & 15.9827 & 1.1902 \\
\hline $\mathrm{F} 4$ & 29 & 0.392 & 0.465 & 15.6986 & 1.1862 \\
\hline F5 & 29 & 0.395 & 0.468 & 15.5982 & 1.1848 \\
\hline F6 & 30 & 0.385 & 0.472 & 18.4322 & 1.2259 \\
\hline
\end{tabular}

Table 3: Results of post-compression parameters

\begin{tabular}{lllllll}
\hline Formulations & Weight variation (mg) & Friability (\%) & Thickness $(\mathbf{m m})$ & Diameter $(\mathbf{m m})$ & Hardness $\left(\mathbf{k g} / \mathbf{c m}^{2}\right)$ & Drug content \\
\hline F1 & $206 \pm 5$ & 0.658 & $4.12 \pm 0.3$ & $8.02 \pm 0.4$ & 5.6 & $98.53 \pm 0.71$ \\
F2 & $208 \pm 6$ & 0.478 & $4.15 \pm 0.5$ & $8.09 \pm 0.3$ & 5.8 & $98.43 \pm 0.81$ \\
F3 & $208 \pm 9$ & 0.689 & $4.15 \pm 0.4$ & $8.02 \pm 0.5$ & 5.7 & $99.13 \pm 0.31$ \\
F4 & $206 \pm 4$ & 0.478 & $4.21 \pm 0.2$ & $8.09 \pm 0.5$ & 5.8 & $99.83 \pm 0.21$ \\
F5 & $205 \pm 5$ & 0.698 & $4.12 \pm 0.1$ & $8.22 \pm 0.4$ & 5.9 & $99.13 \pm 0.41$ \\
F6 & $204 \pm 7$ & 0.989 & $4.23 \pm 0.2$ & $8.02 \pm 0.2$ & 5.8 & $98.23 \pm 0.81$ \\
\hline
\end{tabular}


Table 4: Results of mathematical modeling

\begin{tabular}{lllllll}
\hline Batch & $\begin{array}{l}\text { Zero } \\
\text { order }\end{array}$ & $\mathbf{1}^{\text {st } \text { order }}$ & Matrix & Peppas & $\begin{array}{l}\text { Hix. } \\
\text { Crow }\end{array}$ & $\begin{array}{l}\text { N value } \\
\text { K value }\end{array}$ \\
\hline F1 & 0.9672 & 0.9677 & 0.9881 & 0.9990 & 0.9675 & 0.6510 \\
& & & & & & 0.1026 \\
F2 & 0.9764 & 0.9767 & 0.9838 & 0.9994 & 0.9766 & 0.6926 \\
& & & & & & 0.0936 \\
F3 & 0.9764 & 0.9767 & 0.9838 & 0.9994 & 0.9766 & 0.7143 \\
& & & & & & 0.0866 \\
F4 & 0.9694 & 0.9698 & 0.9875 & 0.9994 & 0.9797 & 0.7024 \\
& & & & & & 0.0909 \\
F5 & 0.9772 & 0.9776 & 0.9830 & 0.9987 & 0.9675 & 0.7340 \\
& & & & & & 0.0830 \\
F6 & 0.9662 & 0.9667 & 0.9849 & 0.9979 & 0.9765 & 0.7442 \\
& & & & & & 0.0809 \\
\hline
\end{tabular}

formulations were found to be $204 \pm 7-210 \pm 4 \mathrm{mg}$. The weight variation is presented, Table 3 .

In vitro drug release decreases with an increase in gum concentration. This may be due to the fact that at a higher concentration of gum, there is the formation of the dense matrix which reduces the mobility of drug particles and slow down the dissolution rate [12]. With f3 formulation giving $72.18 \%$ release after $8 \mathrm{~h}$ and formulation f1 containing 15\% Mardi gum showed about $80 \%$ release after $8 \mathrm{~h}$. In vitro drug release profile of all the formulation batches is shown in Figs. 3 and 4.

The release data as given in Table 4 were fitted to various mathematical models to evaluate the kinetics and mechanism of drug release. The kinetic data of all formulations f1-f6 could be best expressed by the zero-order equation as the plots showed the highest linearity $\left(\mathrm{R}^{2}: 0.966-0.977\right)$. The $\mathrm{n}$ values obtained from Korsmeyer-Peppas plots range from 0.692 to 0.744 indicate that mechanism of release from formulations $\mathrm{f} 1$ to $\mathrm{f} 6$ was polymer diffusion and erosion (anomalous [non-Fickian] diffusion).

\section{CONCLUSION}

The experimental data of the presentresearch work carried out indicated the potential of Mardi gum (T. tomentosa) as a release retardant agent in the formulation of sustained release tablets of alprazolam. In vitro release studies of formulation $\mathrm{f} 1-\mathrm{f} 6$ showed, formulation $\mathrm{f} 3$ containing the maximum amount of gum release the drug in a controlled and sustained manner with the maximum amount of 98.02\% drug in $14 \mathrm{~h}$. Hence, it is concluded that Mardi gum (T. tomentosa) can be utilized as a natural matrix forming agent in the formulation of sustained released tablets.

\section{ACKNOWLEDGMENTS}

Authors are thankful to Dr. G. R. Shendarkar for supporting me throughout the research and Principal Nanded Pharmacy College, Nanded, for providing facilities to conduct the studies.

\section{AUTHORS' CONTRIBUTIONS}

Mangesh Kumare carried out the experiment. Giridhar Shendarkar directed the project

\section{CONFLICTS OF INTEREST}

No conflicts of interest related with this work.

\section{AUTHORS' FUNDING}

Author received financial support (Rajiv Gandhi National Fellowship for 2 years) for research work but no financial support for the authorship and/or publication of this article.

\section{REFERENCES}

1. Mohsen A, Khoweysa OM, Shoukri RA. Optimization of aceclofenac once daily matrix tablets: In-vitro and in-vivo studies. J Pharm Res Opin 2012;2:12-22

2. Niranjan $\mathrm{P}$, Shanmugam S, Vetrichelvan T. Formulation and in-vitro evaluation of sustained release matrix tablets of ibuprofen. Res J Pharm Biol Chem Sci 2013;4:1656-64.

3. Alderman DA. A review of cellulose ethers in hydrophilic matrices for oral controlled release dosage forms. Int J Pharm 1984;5:1-9.

4. Yu L, Dean K, Li L. Polymer blends and composites from renewable resources. Prog Polym Sci 2006;31:576-602.

5. Kumare MM, Shendarkar GR. Isolation, purification and characterization of the gum exudates from Mardi (Terminalia tomentosa). Int J Pharm Bio Sci 2018;8:107-112.

6. Nandhini J, Rajalakshmi AN. Formulation development and evaluation of methylprednisolone dispersible tablets. Asian J Pharm Pharmacol 2018;4:514-21.

7. Kokate CK, Purohit AP, Gokhale SB. Pharmacognosy. Vol. 24. Pune: Nirali Prakashan 2003.

8. Cooper J, Gunn G. Powder flow and compaction. In: Carter SJ, editor. Tutorial Pharmacy. New Delhi, India: CBS Publishers and Distributers; 1986. p. 211-33.

9. Shah D, Shah Y, Rampadhan M. Development and evaluation of controlled release diltiazem hydrochloride microparticles using crosslinked polymer (vinyl alcohol). Drug Dev Ind Pharm 1997;23:567-74.

10. Aulton ME, Well TI. Pharmaceutics. In: The Sciences of Dosage form Design. London, England: Churchill Livingstone; 1998.

11. Gunjal PT, Shinde MB, Gharge VS, Pimple SV, Gurjar MK, Shah MN. Design, development and optimization of S (-) atenolol floating sustained release matrix tablets using surface response methodology. Indian J Pharm Sci 2015;77:563-72.

12. Bharadwaj TR, Kanwar M, Lal R, Gupta A. Natural gums and modified natural gums as sustained-release carriers. Drug Dev Ind Pharm 2000;26:1025-38. 